\title{
Mitochondria-associated satellite I RNA binds to hnRNP K protein
}

\author{
Karolina Klimek-Tomczak, Michał Mikula, Artur Dzwonek, Agnieszka Paziewska, \\ Lucjan S. Wyrwicz, Ewa E. Hennig and Jerzy Ostrowski ${ }^{\bowtie}$ \\ Department of Gastroenterology, Medical Center for Postgraduate Education and the Maria Skłodowska-Curie \\ Memorial Cancer Center and Institute of Oncology, Warszaw, a Poland; ${ }^{\circledR}$-mail: jostrow@warman.com.pl
}

Received: 31 August, 2005; revised: 28 December, 2005; accepted: 02 January, 2006

available on-line: 23 February, 2006

\begin{abstract}
hnRNP K protein, which localizes to the nucleus, cytoplasm and mitochondria, is involved in the various cellular processes that compose gene expression. We used a SAGE-based assay to profile RNAs associated with hnRNP $K$ protein in rat mitochondria. RNA was isolated from mitoplasts obtained from highly purified and RNase-treated mitochondria. Total RNA and RNA associated with hnRNP $K$ protein were then used as input material for generating two SAGE libraries. Mitochondrion-derived tags isolated from the total mitoplast RNA library represented $86.3 \%$, while those isolated from the library constructed from RNA associated with hnRNP K protein represented only $28.2 \%$ of selected tags. Thus, an unexpected number of nuclear-encoded RNAs were purified from mitochondria. Many of these transcripts were co-purified with hnRNP K protein, and high levels of nuclear-encoded RNAs co-immunoprecipitating with $\mathrm{K}$ protein corresponded to elevated hnRNP K protein levels of the organelle. The most abundant RNAs that were copurified with hnRNP K protein represented transcripts originating from satellite I DNA. While satellite I RNA levels were higher in the nucleus and cytoplasm than in mitochondria, the most abundant binding of satellite I transcripts to hnRNP $\mathrm{K}$ protein was found in mitochondria. The role of satellite I RNA in mitochondria remains to be elucidated.
\end{abstract}

Keywords: SAGE, hnRNP K protein, satellite I RNA, mitochondria

The multimodular hnRNP $\mathrm{K}$ protein is one of at least 20 components of the hnRNP particle (Swanson \& Dreyfuss, 1988; Bomsztyk et al., 2004) that is formed by the stable association of pre-mRNA and mRNA with hnRNP proteins. The association of hnRNP proteins with RNAs begins on the nascent transcript and this complex usually persists until translation initiation. hnRNP proteins are recruited to different transcripts probably at different levels of affinity and are involved in the mRNA maturation, its nuclear export, subcellular localization, translation and stability. Ribonucleoprotein complexes appear to be highly dynamic (Dreyfuss et al., 2002), and it is thought that a unique arrangement of hnRNP proteins is formed on every mRNA. Thus, factors determining the constitution of RNP complexes depend on specific mRNA sequences bound by RNAbinding proteins. Some RNAs interact with hnRNP proteins highly specifically, and these interactions occur with high affinity. Other RNAs can be bound to RNA-binding proteins nonspecifically showing much lower binding affinity (Swanson \& Dreyfuss, 1988).

The vast majority of mitochondrial proteins are encoded in the nuclear genome. Some are localized exclusively to mitochondria, while others can also be found in other subcellular compartments (Mootha et al., 2003). Nuclear-encoded proteins imported to mitochondria can be directed to the outer mitochondrial membrane either post- or co-translationally (Crowley et al., 1998). Their synthesis can be initiated and completed on cytoplasmic ribosomes or translation can be initiated by cytoplasmic ribosomes, after which the transcript is directed to mitochondria by the amino-terminal peptide, where translation is completed (Lightowlers et al., 1996;

Abbreviations: coIP, co-immunoprecipitation; ER, endoplasmic reticulum; FBS, fetal bovine serum; GFP, green fluorescent protein; hnRNP, heterogeneous nuclear ribonucleoprotein; HTC-IR, rat hepatoma cells expressing human insulin receptor; PCR, polymerase chain reaction; RNP, ribonucleoprotein; SAGE, serial analysis of gene expression. 
Pfanner \& Geissler, 2001; George et al., 2002; Mootha et al., 2003). Synthesis of another class of nuclearencoded mitochondrial proteins takes place in the vicinity of the organelle where their mRNAs are bound to mitochondria before the initiation of translation (Mili et al., 2001; Rospert et al., 2002; Sylvestre et al., 2003).

Mitochondrial import of RNA from the cytoplasm is thought to be wide-spread among various species (Dietrich et al., 1996; Kumar et al., 1996). Mitochondrial tRNA import has been demonstrated in a number of evolutionarily distinct organisms, such as yeast, protozoans, mammals and plants (Delage et al., 2003). Some other nuclear-encoded RNA transcripts, including $5 \mathrm{~S}$ ribosomal RNA (Yoshionari et al., 1994; Entelis et al., 2001) and RNA components of RNase P (Doersen et al., 1985; Puranam \& Attardi, 2001) or RNase MRP (Chang \& Clayton, 1987) endonucleases are also targeted to mammalian mitochondria.

A recent study from our laboratory, performed on total cellular extracts, showed that hnRNP K protein interacts with both coding and non-coding mitochondrial transcripts by direct and indirect binding (Klimek-Tomczak et al., 2004). To further explore interactions between mitochondrial RNAs and hnRNP $\mathrm{K}$ protein, we used a SAGE based assay to profile RNAs associated with hnRNP $\mathrm{K}$ protein in mitoplasts obtained from highly purified mitochondria. Unexpectedly, we found that several nuclear-encoded RNAs can access the RNase-insensitive mitochondrial compartments. The most abundant RNAs that were found among those interacting with the mitochondrial hnRNP K protein represented transcripts originating from satellite I DNA. Increased levels of nuclear-encoded RNAs co-purified with $\mathrm{K}$ protein were concomitant with elevated hnRNP $\mathrm{K}$ protein level of the organelle.

\section{MATERIALS AND METHODS}

Cells. Rat hepatoma cells expressing human insulin receptor (HTC-IR) were grown in plastic cell culture flasks in DME media supplemented with $10 \%$ FBS, $2 \mathrm{mM}$ glutamine, penicillin (100 units $/ \mathrm{ml}$ ), streptomycin $(0.01 \%)$, and humidified with $6 / 94 \%$ $\mathrm{CO}_{2} /$ air gas mixture.

Isolation of mitochondrial fractions. Polysome-free and polysome-bound mitochondria were purified from cells by differential centrifugation on a sucrose gradient as described previously (Ostrowski et al., 2004). Total RNA was prepared from subcellular fractions using TRIzol reagent and was further purified with RNeasy mini columns (Qiagen).

To obtain RNase-insensitive compartments of mitochondria, freshly prepared mitochondria suspended in an isotonic sucrose buffer $(0.25 \mathrm{M}$ sucrose, $1 \mathrm{mM}$ EDTA, $10 \mathrm{mM}$ Tris/ $\mathrm{HCl}, \mathrm{pH}=7.4,10$ $\mu \mathrm{g} / \mathrm{ml}$ leupeptin, $0.5 \mathrm{mM}$ phenylmethylsulfonyl fluoride, $0.5 \mathrm{mM}$ dithiothreitol, $30 \mathrm{mM} p$-nitrophenyl phosphate, $10 \mathrm{mM} \mathrm{NaF}, 0.1 \mathrm{mM} \mathrm{Na} \mathrm{VO}_{4}, 0.1 \mathrm{mM}$ $\mathrm{Na}_{2} \mathrm{MoO}_{4}$ and $10 \mathrm{mM} \beta$-glycerophosphate) were exposed to RNase A $(0.1 \mathrm{mg} / \mathrm{ml})$ for $30 \mathrm{~min}$ at $25^{\circ} \mathrm{C}$ or RNase A plus RNaseIII $(0.1 \mathrm{mg} / \mathrm{ml})$ for $30 \mathrm{~min}$ at $37^{\circ} \mathrm{C}$. The mitochondrial fraction was then purified by centrifugation through a 1.0/1.5 $\mathrm{M}$ discontinuous sucrose gradient. Next, mitochondria diluted 10fold with hypotonic buffer $(5 \mathrm{mM}$ Tris/ $\mathrm{HCl}, \mathrm{pH}=7.4$ and $1 \mathrm{mM}$ EDTA) containing inhibitors of proteases, phosphatases and RNases (200 units $/ \mathrm{ml}$ ) were centrifuged at $14000 \times \mathrm{g}$ for $20 \mathrm{~min}$ at $4^{\circ} \mathrm{C}$. The pellet of mitoplasts was washed three times with hypotonic buffer.

RNA co-immunoprecipitation. RNA was co-purified with $\mathrm{K}$ protein using anti-K protein antibody \#54 directed against its $\mathrm{C}$ terminus as described previously (Klimek-Tomczak et al., 2004). Phenol-purified and ethanol-precipitated RNA pellets were further purified using RNeasy mini columns (Qiagen) after on-column DNase digestion with the RNase-free DNase set (Qiagen).

SAGE. SAGE libraries were generated following the SAGE procedure v1.0e (http://www. sagenet.org) and the protocol for I-SAGE Kit, Version A (Invitrogen) with some modifications, as described recently (Klimek-Tomczak et al., 2004). Briefly, mitoplast total RNA and RNA co-immunoprecipitated with $\mathrm{K}$ protein were reverse transcribed to cDNA and PCR-amplified according to the procedures from the Clontech SMART PCR cDNA Synthesis Kit User Manual. Then, $2 \mu \mathrm{g}$ of PCR-amplified cDNA was digested with Hsp92II instead of NlaIII (both enzymes recognize the same four-base restriction site, CATG), and the biotinylated 3' cDNA ends were isolated using streptavidin-coated magnetic beads. After ligation to $5^{\prime}$-biotinylated oligonucleotide linkers $\mathrm{A}$ and $\mathrm{B}, \mathrm{cDNA}$ tags were released by digestion with BsmFI and blunt-ended using Klenow fragment DNA polymerase. Two pools of cDNA tags were then ligated to generate ditags flanked by linkers A and B. Ditags were PCR-amplified using biotinylated primers. Amplified ditags were ethanol-precipitated, digested with Hsp92II, and the biotinylated linkers were removed using streptavidin beads. The released ditags were further purified by polyacrylamide gel electrophoresis. Gel-purified ditags were ligated to generate concatamers, which were size-fractionated on $8 \%$ polyacrylamide gel. Gel regions between 500 and $1200 \mathrm{bp}$ were excised, concatamers were isolated and cloned into pZero-1 (Invitrogen) vector. Bacterial colonies were tested for the quality of inserts by PCR. DNA sequencing was performed on 
an ABI Prism 377 automated DNA sequencer (Applied Biosystems).

Real-time RT-PCR. Total RNA and RNA coimmunoprecipitated with $\mathrm{K}$ protein was reverse transcribed using SuperScript II RT polymerase (Invitrogen) and random hexamers in a volume of 20 $\mu l$ as per manufacturer's protocol. The real-time PCR used the double-stranded DNA-specific dye SYBR Green I. The reaction mixture contained template DNA, $12.5 \mu \mathrm{l}$ 2X SYBR Green PCR Master Mix (Applied Biosystems), and $50 \mathrm{nM}$ primers (listed below) in a final volume of $25 \mu \mathrm{l}$ (Mikula et al., 2003). Amplification, data acquisition and analysis were carried out using a GeneAmp 7000 Sequence Detection System (Applied Biosystems). In each run, standard curves were generated for a primer set by serial dilution of known quantities of plasmid DNA encoding the respective cDNAs. To ensure that the PCR reactions yielded the correct amplicons, melting curves were generated after each run to verify the melting temperature of the amplicon, and the producs of RT-PCR were additionally verified by running the PCR products on an agarose gel.

Primers to rat genes:

unknown gene (NM_199098)

GGAACCAATGGAGGAGTCACA fwd

CACCGAGTAGGCTGGAGACAA rev

Atp5g1 (NM 017311)

ACCACGAAGGCACTGCTCAT fwd

CCTGGTACAGGAGCGGATCA rev

Aldh3a1 (NM_031972)

AAGCCCTTGTTACGTGGACAA fwd

CGCCTGCAAGCCACATCTA rev

Rpl39 (NM_012875)

CCTCGCCATGTCTTCTCACA fwd

TTTGCCAGGAATCGCTTG rev

Atp6n1a (NM_031604)

AGTGAACAACCATCGCCACC fwd

TCATCTCCTCGCTTCGGAAA rev

Atp61 (NM_130823)

GGCCTGGTGGTTGCAGTACT fwd

GGTGATGCCATCAGTCAGGG rev

smagp (NM_182817)

ACCTACCGGCCACACCTTCT fwd

GAAAAACCGGCGTGGTCAT rev

satellite I DNA

ACTTATTACTACTGCGGCCCA fwd

AATTTGGTGAGCCGAATCTG rev

$\sec 61 \alpha$ (NW_047694)

TTCAATGGAGCCCAAAAGTTG fwd

CCCGTCATCACGTACACAATG rev

Adenovirus construction and infection. Murine hnRNP K protein cDNA was inserted into pAdTrack vector, and HTC-IR cells were transfected as previously described (Ostrowski et al., 2004).
Computational analysis of SAGE results. Tags were identified from sequenced inserts using procedures described by Lash (Lash et al., 2000). Due to the limited repertory of RNA transcripts in the library, the initial procedure described by Lash and coworkers was modified by omitting the removal of the replicated ditag. The 10-base tags neighboring the NlaIII site were extracted and the number of occurrences of each tag was counted. The tag-to-gene assignment was performed by matching tags to transcripts from the RefSeq database (NCBI Reference Sequences, http://www.ncbi.nlm.nih.gov/RefSeq/) and expressed-sequence tags (UniGene EST clusters, http://www.ncbi.nlm.nih.gov/UniGene). Hsp92II restriction sites were mapped to the rat mitochondrial genome sequence (GenBank accession NC_001665); tags of mitochondrial origin were grouped by the position of the neighboring Hsp92II site.

\section{RESULTS}

Profiling mitoplast RNAs using a SAGE-based strategy

SAGE is a strategy used to profile large-scale patterns of gene expression designed not only to identify mRNAs, but also to determine their relative levels (Velculescu et al., 1995). It involves the sequencing of a 14-bp SAGE tag that in principle should represent only one unique transcript, and the number of times the same tag is found reflects the level of expression of the given transcript (Pleasance et al., 2003). Tag-to-gene assignment, or tag mapping, can be done by the use of publicly accessible computational resources (Lash et al., 2000).

We used a SAGE-based assay (Klimek-Tomczak et al., 2004) to define RNAs that are associated with hnRNP $\mathrm{K}$ protein in mitochondria. Total RNA and RNA associated with hnRNP $\mathrm{K}$ protein was isolated from mitoplasts and used as input material for generating libraries for establishment of the two SAGE profiles. Mitoplasts were obtained from highly purified and RNase-treated mitochondria, and their lysate was immunoprecipitated with an antiK protein antibody (Ades \& Butow, 1980; KlimekTomczak et al., 2004). Figure 1 presents a summary of SAGE analyses of the two libraries. SAGE profiles of individual tags are also available as supplementary data (http://lucjan.bioinfo.pl/supplemental/tomczak_2005).

Mitochondria are surrounded by an outer and an inner membrane. The outer membrane is fairly permeable, while the inner membrane maintains the electrochemical gradient necessary for proton-driven ATP production. The inner membrane is embedded 
A.

\begin{tabular}{|c|c|c|c|c|}
\hline \multirow{2}{*}{} & \multicolumn{2}{|c|}{ Total mitoplast RNA } & \multicolumn{2}{c|}{ coIP RNA } \\
\cline { 2 - 5 } & Tags & Tag count & Tags & $\begin{array}{c}\text { Tag } \\
\text { count }\end{array}$ \\
\hline Mitochondrial genome tags & 40 & 876 & 32 & 294 \\
\hline SageMap matched transcripts & 15 & 29 & 160 & 228 \\
\hline Uimnatched & 34 & 109 & 229 & 525 \\
\hline Total tags & $\mathbf{8 9}$ & $\mathbf{1 0 1 4}$ & $\mathbf{4 2 1}$ & $\mathbf{1 0 4 7}$ \\
\hline
\end{tabular}

B.

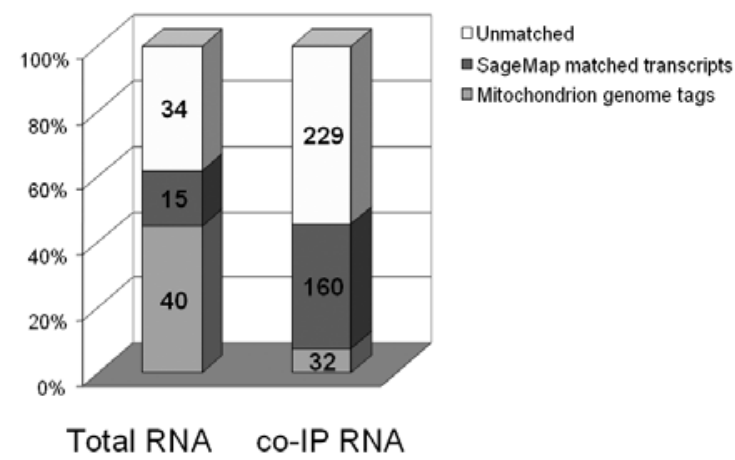

Figure 1. Summary of SAGE results of RNAs bound to hnRNP K protein.

with carriers that transport ions and other substrates (Argyropoulos \& Harper, 2002). Mitochondrionderived tags isolated from the total mitoplast (mitochondria with disrupted outer membrane) RNA library represented $86.3 \%$ of total tags (876/1014), while those isolated from the library constructed from RNA co-immunoprecipitated with hnRNP K protein (coIP RNA library) represented only $28.1 \%$ of total tags (294/1047) (Fig. 1A). The NlaIII cleavage site is palindromic and, therefore, the enzyme can create two tags, each corresponding to one transcribed strand of genomic DNA. As expected, a large fraction of the tags isolated from both libraries corresponded to non-coding mitochondrial transcripts $(46.0 \%$ and $29.9 \%$, respectively), since both the heavy and light strands of the mitochondrial genome are transcribed at similar rates (Aloni \& Attardi, 1971).

Out of the 50 possible mitochondrial tags, our studies identified 40 and 32 unique tags from the total RNA and coIP RNA libraries, respectively. Among them, 26 NlaIII sites created a common set of tags identified in both SAGE experiments (representing 799 tag counts for the total RNA library and 269 counts for coIP RNA).

Twenty nine of the 138 (21\%) total RNA library tags and 228 of the $753(30 \%)$ coIP RNA library tags that could not be assigned to mitochondrial genes matched transcripts characterized in current SageMap resources, including mRNAs and ESTs (Lash et al., 2000) (Fig. 1B). Thus, to our surprise, this assay led to the isolation of transcripts encoded by both the mitochondrial and nuclear genomes. A particularly high percentage of nuclear-encoded tags was found to be associated with mitochondrial hnRNP $\mathrm{K}$ protein. The vast majority of these were present only once in one of the SAGE profiles (http://lucjan. bioinfo.pl/supplemental/tomczak_2005).

\section{Satellite DNA transcripts are associated with hn- RNP $\mathrm{K}$ protein in mitochondria}

Chromosome centromeric regions are composed of satellite DNA that is organized in highly repetitive simple tandem sequences (Guy et al., 2000; Jolly et al., 2004). Satellite repeats can be inducibly transcribed (Jolly et al., 2004) from both DNA strands and their transcripts have high affinity for cellular proteins (Renault et al., 1999).

Of the 753 nuclear-encoded tags co-purified with mitochondrial hnRNP K protein, 252 (33.5\%) correspond to transcripts originating from satellite I DNA (Table 1). In contrast, in the total mitoplast RNA SAGE library only two tags corresponding to satellite DNA transcripts were found among the 138 nuclear-encoded tags $(1.4 \%)$.

The modified SAGE strategy was based on PCR amplification (Klimek-Tomczak et al., 2004). Since the nucleotide sequence of the PCR-SAGE primer which was used to amplify the first strand reverse transcription product bore some similarity to both strands of satellite DNA (not shown), it remained a formal possibility that our SAGE libraries could be contaminated with genomic DNA. To exclude this possibility, the mitochondrial RNA input material was used for PCR with both the PCR-SAGE primer and satellite DNA-specific primers. Under such conditions, RNA that had not undergone the reverse transcription reaction was not amplified by PCR (not shown).

Then, the question we addressed was the intracellular distribution of satellite I transcripts. Cel- 


\section{A. total RNA}

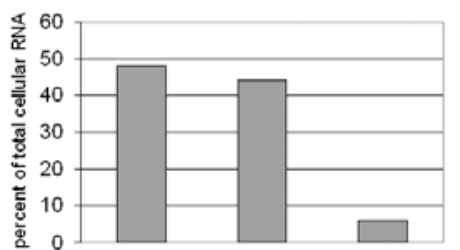

B. coIP RNA

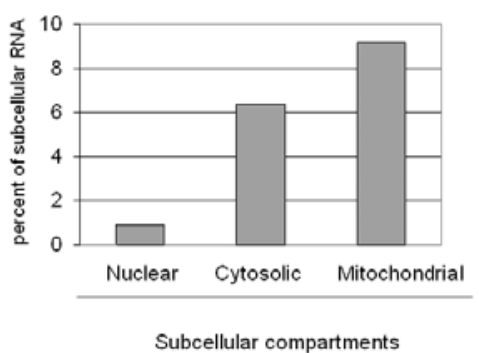

Figure 2. hnRNP K protein-satellite RNA complexes exist in multiple subcellular compartments.

Rat HTR-IC cells were lysed using a Dounce homogenizer in breaking buffer containing protease, phosphatase and RNase inhibitors. The homogenate was centrifuged at 700 $\times g$ for $10 \mathrm{~min}$ at $4^{\circ} \mathrm{C}$, and the resulting supernatants were re-centrifuged under the same conditions. The pellets contained nuclei and cell debris. The post-nuclear supernatant was centrifuged at $10000 \times \mathrm{g}$ for $30 \mathrm{~min}$ at $4^{\circ} \mathrm{C}$. This supernatant (post-mitochondrial fraction) contained the cytoplasm with the endoplasmic reticulum and lysosomes. The mitochondrial pellet was further purified by centrifugation at $80000 \times g$ for $1 \mathrm{~h}$ through a 1.0/1.5 M discontinuous sucrose gradient. Each fraction was divided into two equal aliquots, one used for the isolation of total RNA, and the other for co-immunoprecipitation of RNA with hnRNP K protein. Total RNA (Total) and RNA co-immunoprecipitated with hnRNP K protein $(C o-I P)$ was used for RT-realtime PCR reactions. Results represent the mean of two separate experiments.

lular fractionation was carried out and RNA was co-immunoprecipitated with hnRNP K protein from nuclear, cytosolic and polysome-free mitochondrial compartments using an anti-hnRNP $\mathrm{K}$ protein antibody (Klimek-Tomczak et al., 2004). Next, total RNA from all fractions and RNA eluted from the immunoprecipitates were reverse transcribed and used in real-time PCR. As shown in Fig. 2A, equal amounts of satellite RNA ( $48 \%$ and $44 \%$ of total content of satellite I DNA transcripts, respectively) were found Table 1. Summary of SAGE tags derived from satellite DNA transcripts

\begin{tabular}{lllll}
\hline $\begin{array}{l}\text { NlaIII } \\
\text { site }\end{array}$ & "Plus" strand & $\begin{array}{l}\text { Tag } \\
\text { count }\end{array}$ & „Minus" strand & $\begin{array}{l}\text { Tag } \\
\text { count }\end{array}$ \\
\hline 1 & CGAATCCTAT & 1 & TAATAAGCTT & 101 \\
2 & ATACTTAGAT & 8 & GTGAATTCAG & 45 \\
3 & TCCCATTGGG & 59 & CTTGTATGAG & 5 \\
4 & TTACTCAGAT & 8 & GTGAATTCGG & 25 \\
& & 76 & & 176 \\
\hline
\end{tabular}

in the nuclear and cytosolic fractions, while much less $(7 \%)$ was found in mitochondria. In contrast, the highest binding of satellite I transcripts to hnRNP K protein was detected in mitochondria (Fig. 2B).

The consensus sequence of rat satellite I DNA, deposited in RepBase (Chang \& Clayton, 1987), contains four different NlaIII sites. Since they all appeared to be the anchoring domain (Velculescu et al., 1995), the abundance of satellite transcript tags was calculated by adding all the tags corresponding to satellite I DNA sequence. Seventy six of all these tags were assigned to the plus DNA strand, and 176 tags were mapped to the opposite strand (Table 1). These results indicate that both strands of satellite I DNA are transcribed in HTC-IR cells.

Since satellite I RNAs may form a doublestranded RNA structure which may protect them from digestion with RNase A, we repeated RNA isolation from mitoplasts that were obtained from purified mitochondria treated with either RNase A or both RNase A and RNase III. RNase III is a specific endonuclease which cleaves double-stranded RNA into 12-15 bp fragments. Real-time RT-PCR revealed a similar amount of satellite I RNA in mitoplasts isolated from mitochondria that were treated with RNase A alone compared to those treated with both RNase A and RNase III (3688 (+/-320) and 3512 $(+/-306)$ satellite I RNA copies/10 $10^{6}$ N1 RNA copies, respectively; $\mathrm{n}=2$ ).

We observed several polymorphic forms of the tags of satellite origin (not shown), which may indicate that there are various regions of the rat genome transcribing satellite I DNA. The hypothesis that satellite I DNA may be transcribed from multiple loci could also be confirmed with the use of all four anchoring NlaIII sites located in satellite I repeats. Since the SAGE tag corresponds to a 10 bp sequence associated with $4 \mathrm{bp}$ of the furthest restriction site, such results can suggest heterogenous length of satellite I DNA-derived transcripts.

In conclusion, in HTC-IR rat hepatocytes, satellite I DNA transcripts were found in the nucleus, cytoplasm and mitochondria. A large fraction of mitochondria-associated satellite I RNA is bound to hnRNP K protein.

\section{Determination of RNA levels by RT-real-time PCR}

To verify the relative amounts of the $\mathrm{mR}$ NAs most frequently bound by hnRNP $\mathrm{K}$ protein (Table 2), RNA input material used for generating both SAGE libraries was reverse transcribed and then amplified by real-time PCR. Amplification was carried out using pairs of oligonucleotide primers to: unknown gene, Atp5g1, Aldh3a1, Rpl39, Atp6n1a, Atp61, smagp, and satellite I DNA transcripts. As shown in Fig. 3, real-time RT-PCR revealed that all 


\section{A. total RNA}

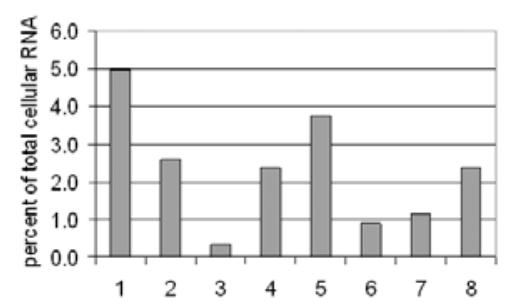

B. colP RNA

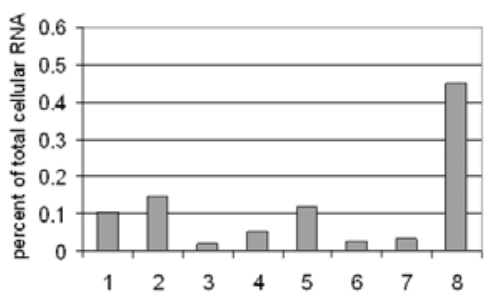

Figure 3. RT-real time PCR confirms that several RNaseinsensitive nuclear transcripts can be extracted from mitoplasts.

RNA input materials (total mitoplast RNA (total RNA; A) and RNA co-immunoprecipitated with $\mathrm{K}$ protein (coIP $R N A$; B) and total cellular RNA used as reference were used for reverse transcription. Real-time PCR reactions were carried out using primers to the protein-coding regions of a rat unknown gene (NM_199098.1), Atp5g1, Aldh3a1, Rpl39, Atp6n1a, Atp61, smagp, and satellite DNA (1-8, respectively). The bars show the relative number of RNA copies in the mitochondrial fractions, expressed as percentage of total RNA levels for a particular gene (mean; $\mathrm{n}=2)$.

studied RNAs could be amplified from both SAGE library input RNAs. The relative amounts of RNAs encoded by the above genes in mitoplasts constituted between $0.32 \%$ and $4.95 \%$ of their total cellular levels (Fig. 3A) indicating that only a small portion of these RNAs can be detected in association with mitoplasts. In contrast, more than $90 \%$ of the mitochondrion-encoded cytochrome $c$ oxidase 2 (Cox2) transcripts, which are restricted to the organelle, were found in mitoplast RNA (not shown). The relative amounts of these RNA co-immunoprecipitated

\section{A. Mitochondrial RNA}

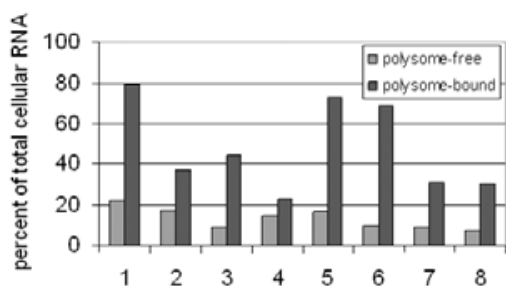

B. Cytosolic RNA

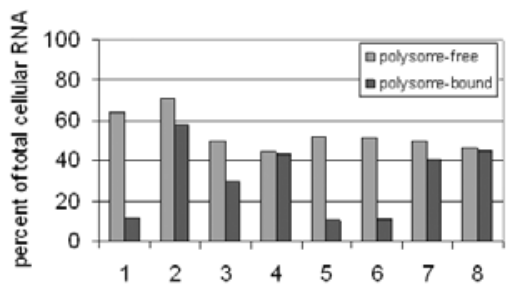

with hnRNP K protein were 6-270 times lower compared to total mitoplast RNA (Fig. 3B). These results also confirmed that among the nuclear-encoded transcripts bound by hnRNP K protein in mitochondria, those representing satellite I RNA are the most abundant.

Mitochondria are tightly coated by polysomes that serve to translate mitochondrial proteins from nuclear-encoded mRNAs (Kellems et al., 1975; Ades \& Butow, 1980; Verner, 1993), and these polysomes are enriched in mRNAs encoding mitochondrial proteins. To determine if the nuclear-encoded transcripts found in mitoplasts are associated with mitochondria-bound polysomes, we prepared lysates from mitochondria, either coated with polysomes or not. Total RNA from polysome-bound and polysome-free mitochondria and corresponding cytosolic fractions was reverse transcribed and then used in real-time PCR. As shown in Fig. 4A, the relative amounts of all tested transcripts were higher in RNA preparations from polysome-bound mitochondria than from the polysome-free mitochondria. In the corresponding cytosolic fractions, the reverse pattern of relative transcript levels was observed (Fig. 4B). Thus, all nuclearencoded RNAs found by SAGE analyses were also associated with the mitochondria-bound polysomes.

It is a known fact that mitochondrial membranes can fuse with other organelles, such as the endoplasmic reticulum, the nuclear and plasma membranes (Cohen et al., 1973), and the close association of a fraction of the ER with mitochondria probably has a physiological role (Ades \& Butow, 1980). Thus, it remained possible that the nuclear-encoded RNAs identified in the mitochondrial matrix could have contaminated SAGE RNA input material.

Sec61 $\alpha$ is a highly conserved protein found exclusively in the ER membrane that is part of a complex that anchors ribosomes to this organelle (Kalies et al., 1994); most of sec61 $\alpha$ mRNA is associated with the ER. To exclude the possibility of contamination of mitoplast preparations by ER-associated RNA, the

Figure 4. Selected nuclear-encoded transcripts are directed to mitochondria.

HTC-IR cells grown in serum were Douncehomogenized in breaking buffer (see Materials \& Methods) containing either $10 \mathrm{mM}$ EDTA (polysome-free) or $5 \mathrm{mM} \mathrm{MgCl} / 100 \mathrm{mM} \mathrm{KCl}$ (polysome-bound). All buffers contained inhibitors of proteases, phosphatases and RNases. After serial centrifugations through a sucrose gradient, mitochondrial pellets were used for isolation of total RNA (A). Total RNA was also isolated from cytosolic fractions (B). RNA samples were reverse transcribed and real-time RTPCR reactions were carried out using primers to the same genes as those described in Fig. 2. The bars show relative number of RNA copies in the mitochondrial fractions expressed as the percentage of total RNA levels for a particular gene (mean; $\mathrm{n}=2$ ). 


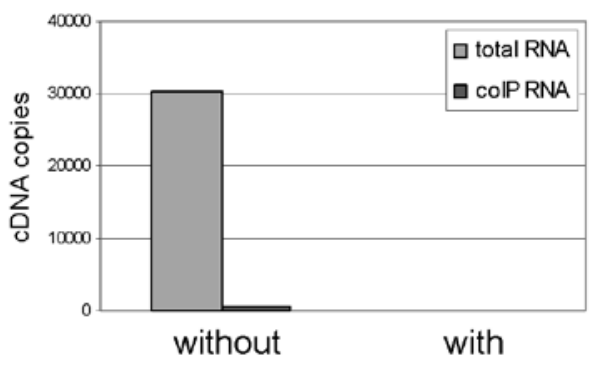

RNase treatment

Figure 5. Mitochondrial $\sec 61 \alpha$ mRNA is sensitive to RNase treatment.

Freshly prepared polysome-free mitochondria suspended in an isotonic sucrose buffer with or without RNase A $(0.1 \mathrm{mg} / \mathrm{ml})$ and treated for $30 \mathrm{~min}$ at $25^{\circ} \mathrm{C}$. Mitochondrial fractions were then purified using centrifugation through a discontinuous sucrose gradient and resuspended in hypotonic buffer. Mitoplast pellets were used for isolation of total RNA or RNA co-immunoprecipitated with K protein. RNA samples were reverse transcribed and real-time PCR reactions were carried out using primers to $\sec 61 \alpha$.

presence of sec61 $\alpha$ mRNA was determined in mitoplast RNA using RT-real-time PCR. As shown in Fig. 5, sec61 $\alpha$ mRNA was not detected in mitoplasts obtained from RNase-treated mitochondria, but it was found in mitoplasts isolated from mitochondria that were not subjected to RNase treatment. Therefore, most likely no nuclear-encoded RNase-resistant RNAs could have accessed the mitochondrial matrix through the ER.

\section{A. Immunoblotting}
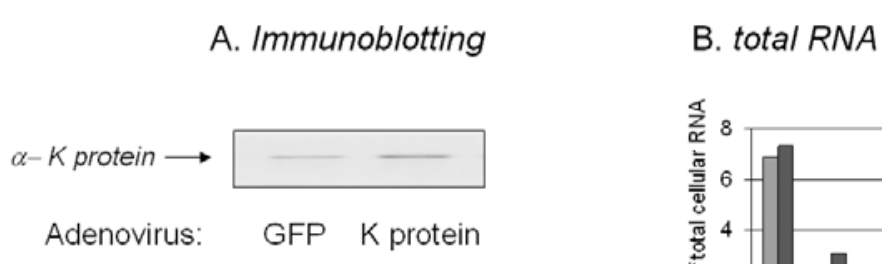

Elevated level of mitochondrial hnRNP K protein increases its association with nuclear-encoded transcripts

SAGE-based analysis of total mitoplast RNA yielded predominantly mitochondrial tags, whereas the analysis of coIP RNA revealed mostly nuclearencoded tags (Fig. 1). To established how the level of hnRNP K protein affects RNA binding, serum-deprived HTC-IR cells were infected with adenoviruses expressing either GFP (control) or hnRNP K protein as described previously (Ostrowski et al., 2004). Cells were harvested, and mitochondria treated with RNase and fractionated on a sucrose gradient were used for mitoplast isolation. Next, protein extracts, total RNA and RNA co-immunoprecipitated with hnRNP K protein were prepared from these mitoplasts.

Transfection of the cells with adenovirus encoding hnRNP $\mathrm{K}$ protein increased $\mathrm{K}$ protein level in the mitoplast lysate (Fig. 6A). Expression of exogenous $\mathrm{K}$ protein did not change the total amount of nuclearly-encoded RNAs in mitoplasts (Fig. 6B) but it did increase the levels of 7 out of 8 RNAs co-purified with hnRNP K protein (Fig. 6C), as compared to control cells. Higher expression of hnRNP K protein led to increased co-immunoprecipitation of RNA. Again, satellite I transcripts showed the highest rate of association with $\mathrm{K}$ protein in mitoplasts isolated from cells transfected with adenovirus expressing hnRNP K.

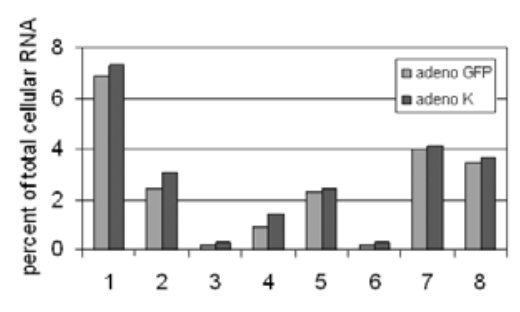

C. COIP RNA

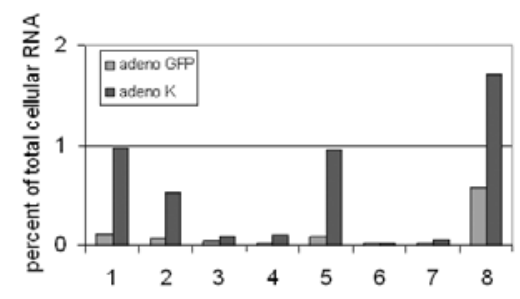

Figure 6. Expression of exogenous hnRNP K protein increases levels of RNase-insensitive $\mathrm{K}$ protein-associated mRNA in mitoplasts.

Serum-deprived HTC-IR cells infected with either GFP (adeno-GFP) or K protein (adeno-K) adenovirus were used for mitoplast isolation from polysome-free and RNase-treated mitochondria. Next, mitoplasts were used for preparation of protein lysate (A), total RNA (B), and RNA co-immunoprecipitated with K protein (C). Proteins resolved by electrophoresis were transferred onto a PVDF membrane, and immunostained with anti-K protein antibody using standard methods. Total RNA and co-IP RNA were reverse transcribed and real-time PCR was carried out using primers to the genes described in Fig. 2. The bars represent the relative number of copies of transcripts expressed as the percentage of total cellular RNA (mean; $\mathrm{n}=2$ ). 
Table 2. List of selected SAGE tags, corresponding to nuclear-encoded mRNAs interacting with hnRNP K protein

\begin{tabular}{|c|c|c|c|c|}
\hline & Tag & Total & Note & Cellular compartment \\
\hline 1 & GTGGCTCACA & 5 & Unknown gene product & Membrane \\
\hline 2 & CCAGTCCTGG & 2 & $\begin{array}{l}\text { ATP synthase, } \mathrm{H}+\text { transporting, mitochondrial F0 complex, } \\
\text { subunit c, isoform } 1 \text { (Atp5g1) }\end{array}$ & Mitochondrion \\
\hline 3 & GAGCCTCATC & 4 & Aldehyde dehydrogenase family 3 , member A1 (Aldh3a1) & Cytosol, mitochondrion \\
\hline 4 & TCTTCTCACA & 3 & Ribosomal protein L39 (Rpl39) & Cytosol \\
\hline 5 & CTGACCCCAG & 3 & $\begin{array}{l}\text { ATPase, } \mathrm{H}+\text { transporting, lysosomal noncatalytic accessory } \\
\text { protein 1a (Atp6n1a) }\end{array}$ & Cytosol, membrane \\
\hline 6 & GGAGCTGCCT & 1 & $\begin{array}{l}\text { ATPase, } \mathrm{H}+\text { transporting, lysosomal (vacuolar proton } \\
\text { pump) } 16 \mathrm{kDa} \text { (Atp6l) }\end{array}$ & Cytosol, membrane \\
\hline 7 & GGTGGATAGG & 2 & $\begin{array}{l}\text { Small cell adhesion } \\
\text { glycoprotein (smagp) }\end{array}$ & $?$ \\
\hline
\end{tabular}

\section{DISCUSSION}

The heterogeneous nuclear ribonucleoprotein $\mathrm{K}$, hnRNP $\mathrm{K}$, is an RNA-binding protein involved in many processes that make up gene expression, including mRNA processing and translation (Bomsztyk et al., 2004). It is localized to the nucleus, cytoplasm and mitochondria (Ostrowski et al., 2002; KlimekTomczak et al., 2004) where it interacts with a large repertory of RNAs, associations that are responsive to ligands such as insulin (Ostrowski et al., 2001).

Mammalian mitochondria are composed of approx. 1000 different proteins, largely encoded by the nuclear genome. Some are synthesized by cytoplasmic ribosomes, whereas others are synthesized in the vicinity of the organelle (Lightowlers et al., 1996; Mili et al., 2001; Pfanner \& Gessler, 2001; George et al., 2002; Rospert et al., 2002; Mootha et al., 2003; Sylvestre et al., 2003), and their mRNAs must be transported from the nucleus to the site of translation. hnRNP $\mathrm{K}$ protein not only associates with transcripts, but also interacts with protein factors that regulate chromatin remodeling, transcription, mRNA processing and translation (Bomsztyk et al., 2004). It may regulate the expression of specific genes, such as $u c p 2$, but also coordinate the expression of mitochondrial genes with those nuclear genes that encode mitochondrial proteins (Ostrowski et al., 2004). The mechanistic details of such coordination remain unknown.

These studies have revealed that nuclear-encoded RNAs can access RNase-insensitive compartments of mitochondria. All nuclear-encoded RNAs that associated with hnRNP $\mathrm{K}$ protein inside mitochondria that were identified in the SAGE analyses were also associated to organelle-bound polysomes. Nuclear RNAs that are specifically targeted to mitochondria in association with hnRNP $\mathrm{K}$ protein may use sequence- and/or structure-based criteria for preferential interaction with mitochondrion polys- omes and for selective transport into the mitochondrion. Therefore, it is not surprising that RNA identified as potentially transcribed via mitochondriabound ribosomes and present in the mitochondrial matrix represents a similar subset of the nuclear transcriptome.

Although mechanisms controlling mitochondrial protein import have been relatively well described (Koehler, 2004; Rehling et al., 2004), it is still unclear how the negatively charged RNA molecules can cross the hydrophobic environment of the mitochondrial membranes to arrive at matrix locations. It can only be speculated that they pass the mitochondrial membranes in close association with RNAbinding proteins imported to the organelle.

In this study we have shown that satellite I derived RNAs are bound most frequently by hnRNP $\mathrm{K}$ protein in mitochondria. There is growing evidence that tandemly repeated, highly variable DNA sequences of the eukaryotic genome are transcribed (Harel et al., 1968; Cohen et al., 1973; Epstein et al., 1986; Fornace \& Mitchell, 1986; Gaubatz \& Cutler, 1990; Guy et al., 2000; Jolly et al., 2004); the resulting transcripts are likely non-coding. Some may remain associated with the loci from which they originate (Jolly et al., 2004), while others may be exported to the cytoplasm (Fornace \& Mitchell, 1986). Although the role of satellite transcription has not yet been understood, it is thought that these non-coding, double-stranded RNAs may play a role in heterochromatin formation in yeast and mice (Rudert et al., 1995; Reinhart \& Bartel, 2002) and may be involved in the control of gene expression (Jenuwein 2002; Jolly et al., 2004).

Knowledge about the functions of rat satellite DNA I is limited, and the majority of published reports were produced years before the first sequence of a mammalian genome was published (Witney \& Furano, 1983; 1984; Epstein et al., 1984). The present paper provides the first evidence of its transcription. 
Since it is unlikely that satellite RNA I might be translated inside mitochondria, we can only speculate that the satellite RNA might play some regulatory role in the organelle. However, it cannot be also excluded that nuclear-encoded RNAs imported in close association with hnRNP K protein, including satellite I transcripts, enter mitochondria as "ballast" elements. Thus, functional data related to satellite I RNA remain an important direction of future studies.

\section{Acknowledgement}

We thank Professor Karol Bomsztyk for valuable discussions of this work.

This study was supported by grants from the State Committee for Scientific Research (PBZ-KBN091/P05/2003/40) and from the Polish Pharmacy and Medicine Development Foundation. J.O.'s work was also supported by a SCHOLAR GRANT from the Foundation for Polish Science. L.S.W. is supported by a Fellowship for Young Scientists from the Foundation for Polish Science.

\section{REFERENCES}

Ades IZ, Butow RA (1980) The products of mitochondriabound cytoplasmic polysomes in yeast. J Biol Chem 255: 9918-9924.

Aloni Y, Attardi G (1971) Symmetrical in vivo transcription of mitochondrial DNA in HeLa cells. Proc Natl Acad Sci USA 68: 1757-1761.

Argyropoulos G, Harper ME (2002) Uncoupling proteins and thermoregulation. J Appl Physiol 92: 2187-2198.

Bomsztyk K, Denisenko O, Ostrowski J (2004) hnRNP K: one protein multiple processes. Bioessays 26: 629-638.

Chang DD, Clayton DA (1987) A mammalian mitochondrial RNA processing activity contains nucleus-encoded RNA. Science 235: 1178-1184.

Cohen AK, Huh TY, Helleiner CW (1973) Transcription of satellite DNA in mouse L-cells. Can J Biochem 51: 529532.

Crowley KS, Payne RM (1998) Ribosome binding to mitochondria is regulated by GTP and the transit peptide. $J$ Biol Chem 273: 17278-17285.

Delage L, Dietrich A, Cosset A, Marechal-Drouard L (2003) In vitro import of a nuclearly encoded tRNA into mitochondria of Solanum tuberosum. Mol Cell Biol 23: 40004012.

Dietrich A, Small I, Cosset A, Weil JH, Marechal-Drouard L (1996) Editing and import: strategies for providing plant mitochondria with a complete set of functional transfer RNAs. Biochimie 78: 518-529.

Doersen CJ, Guerrier-Takada C, Altman S, Attardi G (1985) Characterization of an RNase P activity from HeLa cell mitochondria. Comparison with the cytosol RNase P activity. J Biol Chem 260: 5942-5949.

Dreyfuss G, Kim VN, Kataoka N (2002) Messenger-RNAbinding proteins and the messages they carry. Nat Rev Mol Cell Biol 3: 195-205.

Entelis NS, Kolesnikova OA, Dogan S, Martin RP, Tarassov IA (2001) 5S rRNA and tRNA import into human mitochondria. Comparison of in vitro requirements. J Biol Chem 276: 45642-45653.

Epstein DA, Witney FR, Furano AV (1984) The spread of sequence variants in Rattus satellite DNAs. Nucleic Acids Res 12: 973-988.

Epstein LM, Mahon KA, Gall JG (1986) Transcription of a satellite DNA in the newt. J Cell Biol 103: 1137-1144.

Fornace AJ Jr, Mitchell JB (1986) Induction of B2 RNA polymerase III transcription by heat shock: enrichment for heat shock induced sequences in rodent cells by hybridization subtraction. Nucleic Acids Res 14: 57935811.

Gaubatz JW, Cutler RG (1990) Mouse satellite DNA is transcribed in senescent cardiac muscle. J Biol Chem 265: 17753-17758.

George R, Walsh P, Beddoe T, Lithgow T (2002) The nascent polypeptide-associated complex (NAC) promotes interaction of ribosomes with the mitochondrial surface in vivo. FEBS Lett 516: 213-216.

Guy J, Spalluto C, McMurray A, Hearn T, Crosier M, Viggiano L, Miolla V, Archidiacono N, Rocchi M, Scott C, Lee PA, Sulston J, Rogers J, Bentley D, Jackson MS (2000) Genomic sequence and transcriptional profile of the boundary between pericentromeric satellites and genes on human chromosome arm 10q. Hum Mol Genet 9: 2029-2042.

Harel J, Hanania N, Tapiero H, Harel L (1968) RNA replication by nuclear satellite DNA in different mouse cells. Biochem Biophys Res Commun 33: 696-701.

Jenuwein T (2002) Molecular biology. An RNA-guided pathway for the epigenome. Science 297: 2215-2218.

Jolly C, Metz A, Govin J, Vigneron M, Turner BM, Khochbin S, Vourc'h C (2004) Stress-induced transcription of satellite III repeats. J Cell Biol 164: 25-33.

Kalies KU, Gorlich D, Rapoport TA (1994) Binding of ribosomes to the rough endoplasmic reticulum mediated by the Sec61p-complex. J Cell Biol 126: 925-934.

Kellems RE, Allison VF, Butow RA (1975) Cytoplasmic type $80 \mathrm{~S}$ ribosomes associated with yeast mitochondria. IV. Attachment of ribosomes to the outer membrane of isolated mitochondria. J Cell Biol 65: 1-14.

Klimek-Tomczak K, Wyrwicz LS, Jain S, Bomsztyk K, Ostrowski J (2004) Characterization of hnRNP K proteinRNA interactions. J Mol Biol 342: 1131-1141.

Koehler CM (2004) New developments in mitochondrial assembly. Annu Rev Cell Dev Biol 20: 309-335.

Kumar R, Marechal-Drouard L, Akama K, Small I (1996) Striking differences in mitochondrial tRNA import between different plant species. Mol Gen Genet 252: 404411.

Lash AE, Tolstoshev CM, Wagner L, Schuler GD, Strausberg RL, Riggins GJ, Altschul SF (2000) SAGEmap: a public gene expression resource. Genome Res 10: 10511060 .

Lightowlers RN, Sang AE, Preiss T, Chrzanowska-Lightowlers ZM (1996) Targeting proteins to mitochondria: is there a role for mRNA localization? Biochem Soc Trans 24: 527-531.

Mikula M, Dzwonek A, Jagusztyn-Krynicka K, Ostrowski J (2003) Quantitative detection for low levels of Helicobacter pylori infection in experimentally infected mice by real-time PCR. J Microbiol Methods 55: 351-359.

Mili S, Shu HJ, Zhao Y, Pinol-Roma S (2001) Distinct RNP complexes of shuttling hnRNP proteins with premRNA and mRNA: candidate intermediates in formation and export of mRNA. Mol Cell Biol 21: 7307-7319.

Mootha VK, Bunkenborg J, Olsen JV, Hjerrild M, Wisniewski JR, Stahl E, Bolouri MS, Ray HN, Sihag S, Kamal M, Patterson N, Lander ES, Mann M (2003a) In- 
tegrated analysis of protein composition, tissue diversity, and gene regulation in mouse mitochondria. Cell 115: 629-640.

Mootha VK, Lindgren CM, Eriksson KF, Subramanian A, Sihag S, Lehar J, Puigserver P, Carlsson E, Ridderstrale M, Laurila E, Houstis N, Daly MJ, Patterson N, Mesirov JP, Golub TR, Tamayo P, Spiegelman B, Lander ES, Hirschhorn JN, Altshuler D, Groop LC (2003b) PGC-1alpha-responsive genes involved in oxidative phosphorylation are coordinately downregulated in human diabetes. Nat Genet 34: 267-273.

Ostrowski J, Kawata Y, Schullery DS, Denisenko ON, Higaki Y, Abrass CK, Bomsztyk K (2001) Insulin alters heterogeneous nuclear ribonucleoprotein $\mathrm{K}$ protein binding to DNA and RNA. Proc Natl Acad Sci USA 98: 9044-9049.

Ostrowski J, Wyrwicz L, Rychlewski L, Bomsztyk K (2002) Heterogeneous nuclear ribonucleoprotein $\mathrm{K}$ protein associates with multiple mitochondrial transcripts within the organelle. J Biol Chem 277: 6303-6310.

Ostrowski J, Klimek-Tomczak K, Wyrwicz LS, Mikula M, Schullery DS, Bomsztyk K (2004) Heterogeneous nuclear ribonucleoprotein $\mathrm{K}$ enhances insulin-induced expression of mitochondrial UCP2 protein. J Biol Chem 279: 54599-54609.

Pfanner N, Geissler A (2001) Versatility of the mitochondrial protein import machinery. Nat Rev Mol Cell Biol 2: 339-349.

Pleasance ED, Marra MA, Jones SJ (2003) Assessment of SAGE in transcript identification. Genome Res 13: 12031215.

Puranam RS, Attardi G (2001) The RNase P associated with HeLa cell mitochondria contains an essential RNA component identical in sequence to that of the nuclear RNase P. Mol Cell Biol 21: 548-561.

Rehling P, Brandner K, Pfanner N (2004) Mitochondrial import and the twin-pore translocase. Nat Rev Mol Cell Biol 5: 519-530.
Reinhart BJ, Bartel DP (2002) Small RNAs correspond to centromere heterochromatic repeats. Science 297: 1831.

Renault S, Rouleux-Bonnin F, Periquet G, Bigot Y (1999) Satellite DNA transcription in Diadromus pulchellus (Hymenoptera). Insect Biochem Mol Biol 29: 103-111.

Rospert S, Dubaquie Y, Gautschi M (2002) Nascentpolypeptide-associated complex. Cell Mol Life Sci 59: 1632-1639.

Rudert F, Bronner S, Garnier JM, Dolle P (1995) Transcripts from opposite strands of gamma satellite DNA are differentially expressed during mouse development. Mamm Genome 6: 76-83.

Swanson MS, Dreyfuss G (1988) Classification and purification of proteins of heterogeneous nuclear ribonucleoprotein particles by RNA-binding specificities. Mol Cell Biol 8: 2237-2241.

Sylvestre J, Margeot A, Jacq C, Dujardin G, Corral-Debrinski M (2003) The role of the $3^{\prime}$ untranslated region in mRNA sorting to the vicinity of mitochondria is conserved from yeast to human cells. Mol Biol Cell 14: 3848-3856.

Velculescu VE, Zhang L, Vogelstein B, Kinzler KW (1995) Serial analysis of gene expression. Science 270: 484-487.

Verner K (1993) Co-translational protein import into mitochondria: an alternative view. Trends Biochem Sci 18: 366-371.

Witney FR, Furano AV (1983) The independent evolution of two closely related satellite DNA elements in rats (Rattus). Nucleic Acids Res 11: 291-304.

Witney FR, Furano AV (1984) Highly repeated DNA families in the rat. J Biol Chem 259: 10481-1092.

Yoshionari S, Koike T, Yokogawa T, Nishikawa K, Ueda T, Miura K, Watanabe K (1994) Existence of nuclear-encoded 5S-rRNA in bovine mitochondria. FEBS Lett 338: 137-142. 